\title{
CENAS DA CLÍNICA PSICANALÍTICA
}

Resenha do livro Kessler, C.H., Kreisner, B.C. \& Fröhlich, C.B. (Eds.) (2004).

Tramas da clínica psicanalítica em debate. Porto Alegre: Editora da UFRGS

Margareth Schäffer

Universidade Federal do Rio Grande do Sul

O livro Tramas da clínica psicanalítica em debate convoca o leitor a oferecer sua contribuição à leitura e tramar seus próprios caminhos; exige, ainda, um olhar atento sobre as questões de singularidade, subjetivação e criação que atravessa os textos como um fio condutor. Sim, a obra conduz, mas demanda que o leitor entre com seus próprios fios, levando-o a trabalhar na leitura e escuta dos escritos. São esses escritos que me convocaram ao trabalho, cuja resultante passo então a compartilhar com os leitores.

A Clínica (em) debate traz ao público textos resultantes de um evento de extensão, o qual entrelaçou contribuições de várias áreas do conhecimento, tais como psicologia, antropologia, artes, educação, medicina e política. De cunho marcadamente interdisciplinar, no melhor sentido dessa palavra, o livro presenteia o público com reflexões acuradas e abrangentes acerca das mais diversas questões das atividades clínicas e da própria clínica na contemporaneidade. Assim, os artigos publicados nesse livro buscam mostrar os resultados das reflexões realizadas nos eventos da atividade de extensão, procurando "'abrir as janelas' de uma das poucas clínicas de 'portas abertas', na gíria dos trabalhadores da área das políticas de saúde mental" (Kessler, ${ }^{1}$ p.12).

Creio que é interessante apresentar um panorama dos textos que integram o livro, de forma a situar o leitor acerca da pluralidade e riqueza de diálogos estabelecidos pelos autores. Assim, o livro é composto por cinco partes e um posfácio. Na parte I, são discutidos e analisados as temáticas acerca do Cinema: Felicidade; Psicanálise e Educação e Demanda social e Instituição Pública. Já na parte II, entra em questão o Público e o Privado e na parte III as questões sobre Literatura: Todos os nomes; Teatro: Agora é festa e Cinema: De olhos bem fechados. Na parte IV, entram em cena as Configurações Familiares: perspectivas antropológica e clínica; Diálogos Clínicos e Violência Hoje. Na parte V são os Retratos e perspectivas sobre infância e a marginalidade que entram em cena.

As discussões veiculadas pelos textos nos apresentam uma espécie de retrato, de cenas daquilo que compõe o interesse e a necessidade de discutir quando as questões da clínica entram em questão. A clínica provoca bem mais do que uma reflexão sobre seu modo de funcionamento específico, provoca a busca daquilo que na cultura atravessam os sujeitos. Pode ser através de análise de filmes, quando estes "disparam possibilidades de pensar alguns tópicos de nosso tempo" (Kessler, p.19) ou quando nos defrontam com as nossas "cadeias de mieserabilidade" (Assis Brasil, p.27). Mas, pode ser ainda através da sala de aula, quando se analisam as interações sociocognitivas em cooperação com a epistemologia do professor (Sordi, p.44), ou mesmo, no caso específico da clínica, quando dizemos que "a clínica se constrói em ato" e, portanto, quem esta aí implicado está em posição de aprendiz de algo que ao mesmo tempo se constrói e se gesta (Rickes, p. 54). E, finalmente, pode ser quando nos perguntamos sobre a impossibilidade, eficácia ou inadequação do instrumental psicoterápico no atendimento às populações de baixa renda, tendo por pano de fundo uma discussão acerca das dificuldades do diálogo entre antropologia e psicanálise (Trois, p.56).

Outra questão de suma importância é veiculada pelas discussões do livro, a qual diz respeito à psicose e ao laço social, já que não se trata apenas de uma questão de inclusão social ou daquilo que da cultura e do social atravessam constitutivamente esses sujeitos. Trata-se, sobretudo, de propiciar "vias de acesso para a produção de novas significações e inscrições sociais, levando em conta a fratura presente no laço social" (Carvalho da Silva, p. 74).

A seção seguinte, enfatizando as reflexões acerca do público e do privado, abre outras perspectivas de análise, as quais dizem respeito a temas bastante cruciais da nossa contemporaneidade, principalmente quando problematizamos como o público tem mudado suas facetas e como o privado tem, progressivamente se tornado objeto público. Tal discussão parece apontar para uma reconfiguração progressiva do que entendíamos por tais instâncias, provocando, com isso, inclusive novas configurações subjetivas. No que diz respeito à psicanálise, Cardoso (p.89), subsidiado por Arendt, chama a atenção para as confusões que existem entre o conceito de esfera pública e o conceito de esfera social salientando, ainda, que as distinções existentes entre consultório privado e consultório institucional não podem estar alicerçadas na "oposição público-privado, visto que privado caracteriza um espaço fechado onde a palavra não encontra extensão" (idem). Distinção de filigrama, de detalhes? Talvez, mas não é disso mesmo que se trata na psicanálise? Do detalhe, dos fios, dos pequenos discernimentos. É assim que a "clínica psicanalítica institui uma experiência do detalhe. Funda um lugar onde se pode ter o tempo, o espaço e a liberdade de buscar o traço que faz a diferença na leitura que fazemos do mundo" 
(Souza, p.96). É o romance Todos os nomes de Saramago (1997) que provoca essas reflexões, que provoca Os nós dos nomes e muitas reflexões acerca das conexões entre arte, vida e clínica. Tanto Souza, como Peiruque e Vieira nos convocam através de suas tessituras entre os diversos campos - literário, clínico, artístico... - não só a ler o romance de Saramago, o que não é pouca coisa, mas, também, a nos indagarmos sobre nossa existência, nossa quotidianidade, nossa precariedade e, principalmente, sobre a possibilidade que temos de criar, de inventar uma vida. Assim, "o homem tem que inventar sua existência, assim como o senhor José (protagonista do livro) o fez, e esta existência inclui o Outro" (Peiruque, p. 114). "[...] Como isto te custou Sr. José! Tanto e com tamanha intensidade fitaste o desconhecido que não hesitou em devolver-lhe a mirada. Quanta imundíce do corpo e do espírito tiveste que enfrentar para encontrar, em meio a todos os nomes, alguém." (Vieira, p.124).

E agora é festa e já não estamos mais no romance de Saramago, mas no teatro e teatro é ação, é festa que reúne personagens, que realiza desejos, que cria cenas, que entrecruza destinos, que fala das dores, amores e conflitos, que dá palavra indireta aos adolescentes. Giongo (p.131), tomando como objeto de análise Agora é festa de Maria Falkenback, situa o adolescer como um efeito históricocultural da modernidade, sendo um fenômeno contemporâneo. Situa a peça dentro desse contexto e nos "remete a pensar sobre que possibilidades nossa cultura tem oferecido ao trabalho do adolescer" (p.137), principalmente no que diz respeito às possibilidades simbólicas que possam produzir identificações, produção de sujeitos, inscrição de algo próprio. Assim, os espaços de representação na nossa cultura podem acionar inscrições subjetivas não tão alienantes e que dêem suporte à operação psíquica do adolescer. No que diz respeito a um dos espaços maiores de influência/formação do adolescente na atualidade temos a mídia. Mas, quem é a mídia? O que ela fala desses e para esses sujeitos adolescentes? Fischer (p.161) nos alerta acerca da busca de determinados sentidos ou determinadas verdades dos discursos da mídia sobre a adolescência. Tratase, para a autora, de apanhar um momento de um presente que "suporta a herança de uma longa história de produção de verdade do sujeito" (idem). Assim, a autora assinala de forma bastante pertinente como, neste final de século, a mídia emerge na condição de lugar previlegiado de constituição do sujeito, interferindo decisivamente sobre a vida privada dos mesmos. Fazendo uma passagem da mídia para o cinema, temos a análise do filme De olhos bem fechados de Kubrick, onde Mello (p.171), após análise e comparação com o livro que dá origem ao filme, nos coloca frente a algumas reflexões bastante interessantes, principalmente quando ele acentua que Kubrick não mostra, no filme, apenas a história da "destruição de um macho bemsucedido e autoconfiante, mas também promove a ce- lebração do feminino enquanto única possibilidade de minar as estruturas de um mundo em crise por estar alicerçado sobre convenções, valores e estatutos essencialmente masculinos".

Abre-se outra cena ${ }^{2}$ no livro: entra no palco a família, a violência e os diferentes referenciais clínicos na contemporaneidade. E, para nossa surpresa, a cena abre-se com as possibilidades de um diálogo aberto entre Antropologia e Psicologia. Surpresa, sim, pois a diversidade epistemológica, diferenças de objetivos, de objeto e de pouca tradição no diálogo não têm propiciado muitos encontros. Fonseca, valendo-se da obra em que Malinowski, debate com o amigo e biógrafo de Freud (Ernest Jones) a universalidade do complexo de Édipo, Psicanálise e Antropologia, acentua que, guardadas as devidas proporções, "com uma certa dose de humildade dos dois lados e uma escuta atenta, contemplamos juntos narrativas e crenças que compõem nossa realidade e, no diálogo, vamos repensando 'a família' e recriando a cultura" (p.191). Dando continuidade à discussão acerca da família, Falcetto (p.194) pergunta “como é isso de ser antropólogo-terapeuta? Para ela, isso diz respeito ao perguntar, ser curioso acerca da realidade da família, de como ela se constitui e o que é a função-criança para estas. Ressalta, ainda, a questão da circulação das crianças, que enriquece a vida dessas famílias com poucos recursos, mas que deixa marcas em todos. Assim, para a autora "não podemos desprezar a visão da circulação das crianças nas classes sociais pobres na rua como um recurso de rede social para ajudar nos cuidados. É importante despatologizar a experiência individual" (p.201).

A cena se desdobra, se redobra e inaugura outras entradas. Quem entra em cena é o corpo-sentido no autismo, o qual é cartografado a partir de diversos intercessores Freud, Deleuze, Guattari, Rolnik, entre outros - através dos quais a autora questiona o modelo representacional para compreender o sujeito, apontando, ao mesmo tempo, para a "potência estética do sentir que é também uma potência que produz conhecimento, não como representação ou identificação de análogos, mas como criação, invenção, porque emerge da singularidade daquele que sente, age e significa" (Czermak, p.204). Assim, o autismo é indagado a partir dessa perspectiva, situando-o, na sua constituição subjetiva, fora das "estruturas psicológicas" em direção a uma "ontologia do sensível", o que implica, necessariamente, pensar toda a constituição subjetiva do sujeito como "criação", não tratando o autismo como uma estrutura a parte. Trata-se, aqui, de pensar em uma clínica apoiada em Deleuze, como bem ressalta Palombini, bem como de um retorno a Freud "para livrar a psicanálise das amarras da concepção representacionista do psiquismo e realocar o corpo como lugar de produção de sentido" (p.229). O texto convoca o leitor a pensar a psicanálise para além da clínica com neuróticos adultos e para além das concepções representacionistas; assim, aponta que a psicanálise pode apren- 
der muito com outros diálogos e com aqueles que se ocupam da infância ou das psicoses.

Outra cena é aberta e inaugura-se a discussão acerca da violência e do mal-estar atual, onde é pontuado, de forma bastante pertinente, que "onde há só lugar para um, a luta é mortífera para ocupar o lugar de exclusividade" (p.247). Tais palavras desenham um pouco o que é o nosso malestar perante as condições em que nós vivemos e acena para a impotência do sujeito frente a uma época onde está "enfraquecida nossa relação com a palavra" (p.248) e, cuja consequiência é gerar constantes atos de violência; não podendo passar pela palavra, passa-se ao ato no real. E, passar ao ato têm suas consequiências, as quais, muitas vezes, não são muito alentadoras. Vide o filme $O$ invasor, através do qual Seligman (p.263), procurando agenciar algumas discussões acerca de Quem é o marginal?, diz que a questão da violência não é tratada no filme como uma questão isolada, mas como " uma conseqüência de uma sociedade desigual, de uma crise social, política e econômica" (p.271). Além de discutir a violência, o filme parece retratar uma sociedade sem esperanças onde, afinal, ninguém é bom. O autor discute essa falta de perspectivas agenciada pelo filme como uma opção ideológica dos seus criadores, os quais não são os únicos que procuram mostrar um Brasil sem rumos. O convite para esse filme está feito; resta saber se partilharemos das mesmas convicções de seus autores.

O conjunto de cenas/textos que formam a totalidade da obra encerra com uma discussão acerca de como as crianças e adolescentes circulam pelas instituições de atendimento, "pensando em qual rede de serviços sustenta os sujeitos em questão com suas práticas e concepções e quais as conseqüências das mesmas" (p.275). Dentre as diversas questões que esta cena aborda, uma em especial chama a atenção, a qual trata da questão dos laços, principalmente quando o autor enfatiza a criatividade " na construção de saídas que possibilitem a criação de 'laços', uma vez que o laço ao mesmo tempo em que inserido na rede permite um desvio da padronização, a construção da diferença, da criação. Permite a construção de saídas únicas para os sujeitos envolvidos, ao propiciarem a ex- pressão da subjetividade, ao invés da invasão da mesma pela normatização" (pp.278-279).

Finalmente, creio ser interessante pontuar que a diversidade e pluralidade das cenas/textos possui um fio que vai tecendo as diferenças em torno de uma perspectiva de possibilidades, de demarcação dos processos singulares (não individuais) de subjetivação na contemporaneidade, o que comporta, necessariamente uma vertente de criação, de poder fazer algo com os fios que lhe dizem respeito.

\section{Notas}

1. As referências sem data correspondem aos capítulos da obra resenhada.

2. Trato as várias seções do livro como "cenas", procurando, com isso, respeitar a diversidade e pluralidade que a obra nos oferece.

\section{Referência}

Saramago, J. (1997). Todos os nomes. São Paulo: Companhia das Letras.

Margareth Schäffer é Professora Titular da Faculdade de Educação da UFRGS. Endereço para correspondência: FACED. Av. Paulo Gama, s/n Prédio 12201, sala 910, CEP 90.046-900 - Porto Alegre. Rio Grande do Sul (RS) - Brasil. marga@edu.ufrgs.br

O livro é resultado de um curso de extensão realizado pela Clínica de Psicologia da UFRGS.

\section{Resenha: Cenas da clínica psicanalítica}

Margarete Schäffer

Recebido: 23/05/2005

$1^{a}$ revisão: $19 / 10 / 2005$

Aceite final: 26/01/2006 